\title{
Optimal Parameter Estimation of Solar PV Panel Based on Hybrid Particle Swarm and Grey Wolf Optimization Algorithms
}

\author{
Hegazy Rezk ${ }^{1,2 *}$, Jouda Arfaoui ${ }^{3}$, Mohamed R. Gomaa ${ }^{4,5}$ \\ ${ }^{1}$ College of Engineering at Wadi Addawaser, Prince Sattam Bin Abdulaziz University, Wadi Addawaser (Saudi Arabia) \\ ${ }^{2}$ Electrical Engineering Dept., Faculty of Engineering, Minia University, Minia (Egypt) \\ ${ }^{3}$ National School of Engineering of Tunis, BP 37, 1002 Tunis, University of Tunis ELMANAR (Tunisia) \\ ${ }^{4}$ Mechanical Department, Benha Faculty of Engineering, Benha University, Benha (Egypt) \\ ${ }^{5}$ Mechanical Department, Faculty of Engineering, Al-Hussein Bin Talal University, Ma'an (Jordan)
}

Received 20 June 2020 | Accepted 30 October 2020 | Published 14 December 2020

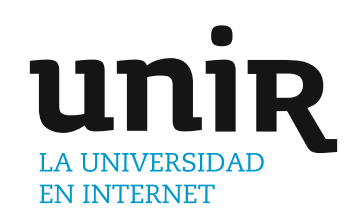

KEYWORDS

Modern Optimization, Parameter Estimation, Renewable Energy, Energy Efficiency, Single-diode Model, Double-diode Model.

DOI: $10.9781 /$ ijimai.2020.12.001

\section{INTRODUCTION}

$\mathrm{T}$ HE expanding need for power and the necessity to save the environment have led to an increased focus on renewable energy resources. Solar energy is addressed as a crucial and promising alternative, especially for the electrical power domain, regarding its merits in terms of availability and cleanliness. In this context, the prevailed tendency is to produce some strategies, aimed at ensuring the effectiveness of photovoltaic devices design. The production chain's effectiveness for electricity relies upon the reliability of solar cells (SCs). For obtaining the maximum output energy, it is mandatory to design accurately and with efficacy the photovoltaic (PV) module

Regarding this matter, a prerequisite is to produce a proper mathematical model and reliable patterning techniques enabling the simulation of the actual behavior of photovoltaic cells or modules. The single diode model (SDM) and the double diode model (DDM) have been considered as the widely employed mathematical models [1]. The PV modeling could prove crucial in achieving an appropriate and

${ }^{*}$ Corresponding author.

E-mail address: hr.hussien@psau.edu.sa effective conception for the PV systems. To assess the efficiency of the PV models, the process of extracting the PV parameters becomes a hard task due to the non-linearity aspect of $(I-V)$ characteristics. To overcome this issue, the estimation procedure of these variables for both SDM and DDM is addressed as a non-linear optimization problem under different operating constraints, aimed to adjust these decision variables.

PV modeling strategies are classified according to either the available data (manufacturers, experimental measures) or the established method, thus obtaining an accurate PV model. In that regard, a variety of approaches are introduced in the literature aimed to extract optimal PV cells parameters of such complex design, and that provides a significantly improved accuracy. These approaches are commonly categorized into three groups: Analytical, numerical, and hybrid methods [2].

Concerning the traditional methods (analytical methods), the identification of PV parameters required elementary functions [3], taking into consideration some points of both $(I-V)$ and $(P-V)$ curves, which are identified as important. These methods have the advantage of being easy to be implemented and having a reduced computational cost. An impressive selection of points offers high-quality solutions. The main drawback of the analytical techniques is using few 
assumptions that are made to reduce the number of the unknown parameters. For this purpose, several deterministic and metaheuristics methods are examined, aimed to assess the efficacy of such PV devices.

The iterative approaches such as newton-raphson with likehood estimator [4], gauss-seidel [5] approaches were applied to solve the restrictions of analytical approaches. Deterministic methods are designed to estimate the parameters which govern the PV model, and they consist of the Levenberg-Marquardt method (LM) [6], NewtonRaphson method [7] and Conductivity Method (CM) [8]. Furthermore, the solutions obtained via these approaches are in heavy dependence on the initial conditions of the unknown parameters and easily catch the local optimal solution. Such methods are not appropriate for parameter extraction of PV models under any environmental conditions. In deterministic method [9], the parameters have been estimated by considering a large number of actual measured data. These methods give a faster response, however, the results accuracy of these methods are yet to improve since deterministic methods follow gradient-based algorithms which will easily dive into the local optimal solution, having more restrictions. Additionally, the precision of these approaches is less as the initial solutions are far from the global best solutions [10].

For more accurate and reliable solutions, soft computing methods are introduced for this purpose, which are based on global optimization theory. Based on the literature, there are several metaheuristics algorithms which can be categorized into four groups: Evolutionarybased algorithms; Swarm intelligence-based algorithms; Physics-based algorithms and Human-based algorithms. Researches highlighted the significance of these methods in parameter extraction of PV SCs such as Genetic algorithm (GA) [11], Artificial Bee Colony (ABC) [12] and other optimizers [13]-[19].

Some strategies suffer from shortcomings regarding: quality of solution (catching the local optimum) and convergence speed; computational execution time (execution time is often longer); performance under different environmental conditions. Recently, hybrid techniques were prevailed in addressing the PV parameter extraction issue. Distinct strategies or different optimization techniques are incorporated, thus forming a hybrid method. Various researchers are focused on the use of hybrid techniques to manage the limitations of the previous methods. For example, in [20], the authors introduced Levenberg-Marquardt algorithm combined with simulated annealing (LMSA) hybrid strategy, which is the result from a combination of LM and SA metaheuristic techniques. The hybrid strategy (EHA-NMS) [21] is based on the combination of the two swarm methods Eagle Strategy (ES), ABC and deterministic NMS (Nelder-Mead simplex) technique.

Authors in [26] proposed a novel hybrid approach based on the Pattern Search method and the Firefly algorithm to extract the parameters of both SDM and DDM. To validate the effectiveness, this new approach was compared with other optimizations algorithms used for the parameters extraction process. The proposed strategy outperforms the considered studies techniques in terms of quality solution and accuracy.

In that context, the particle swarm optimization method (PSO) is considered as the most widely spread metaheuristic (MH) technique due to its ease of implementation. Despite that, this technique suffers from some shortcomings such as the premature convergence and the catching of the local optimum. To avoid these drawbacks, several PSO variants are proposed such as the GA-PSO hybrid method [27], which is generated by the combination of the GA and PSO algorithms, seeking to identify the parameters of the single diode PV modules, this hybrid technique performs better than the classical GA metaheuristic. Another hybrid technique named Guaranteed Convergence Particle
Swarm Optimization (GCPSO) was examined in [28]. The objective of this technique is to estimate the PV parameters of both SDM and DDM, under different functioning conditions. Consequently, the particle swarm stagnation and the premature convergence were evaded. Also, this strategy has exhibited better performance in terms of accuracy and computational time.

In sum, the process of parameters' estimation of PV modules has been proved as a hard challenge by several literature reviews. This problem is reformulated as an optimization problem with constraints, which can be managed effectively thanks to such advanced metaheuristics methods. Many researchers focus on how to invent new methods, which can estimate the unknown parameters of solar cells, with high accuracy as well as non-premature convergence of solutions. In this paper, the parameters of solar PV panel are identified for the first time, as far as the authors know, using hybrid particle swarm optimization (PSO) and grey wolf optimizer (WGO) based on experimental datasets of $I-V$ curves. The chief benefit of hybrid PSOGWO is combining the exploitation ability of the PSO with the exploration ability of the GWO. Three different solar PV modules are considered to prove the superiority of the proposed strategy. Three different solar PV panels are used during the evaluation of the proposed strategy. A comparison of PSOGWO with other state-of-the-art methods is made.

\section{Modelling of PV PANel}

To achieve an effective design of PV systems, a lot of literature review works are looking to develop mathematical modeling of solar PV modules. The single diode model (SDM) is the most commonly used one due to the ease of implementation as well as the compromise reached between the accuracy and simplicity. However, to enhance the accuracy representation, the double diode model (DDM) appeared and is considered for uses, especially under low irradiation.

\section{A. Single Diode Model}

Fig. 1 depicts the electrical equivalent model of a single diode of PV cells. By applying Kirchhoff's law, this model is expressed by Eq (1):

$$
I=I_{p v}-I_{D}-\left(\frac{V+I \cdot R_{S}}{R_{p}}\right)
$$

Where

$I_{\mathrm{pv}}$ and $I_{\mathrm{D}}$ represent the photo-generated current and the diode current, respectively.

$R_{\mathrm{s}}$ and $R_{\mathrm{p}}$ indicate the series and shunt resistance.

A current supply $I_{\mathrm{pv}}$ is linked to a parallel diode $D$ with $(I-V)$ characteristic curve, which is defined by Shockley in the following formula as:

$$
I_{D}=I_{o 1}\left[\exp \left(\frac{\left(V+I \cdot R_{s}\right.}{n_{1} \cdot V_{t}}\right)-1\right]
$$

The ideality factor of such diode is denoted by $n_{1}$, selected according to the sort of semi-conductor material and the fabrication design.

$V_{t}$ represents the thermal voltage, which expresses as follows [29]:

$$
V_{t}=\frac{N_{s} \cdot K \cdot T}{q}
$$

$K$ is the Boltzmann constant and it is equal to $1.35^{*} 10^{-23}$.

$T$ indicates the PV cell temperature, expressed in kelvin.

$N_{\mathrm{s}}$ and $q$ represent the number of PV cell which are connected in series and the charge of electron $\left(1.6^{*} 10^{-19}\right)$.

The model shown in Fig. 1 is characterized by five variables expressed as follows $\left(I_{\mathrm{pv}}, I_{\mathrm{o} 1}, n_{1}, R_{\mathrm{s}}, R_{\mathrm{p}}\right)$, that can be identified by analytic or numerical method. 


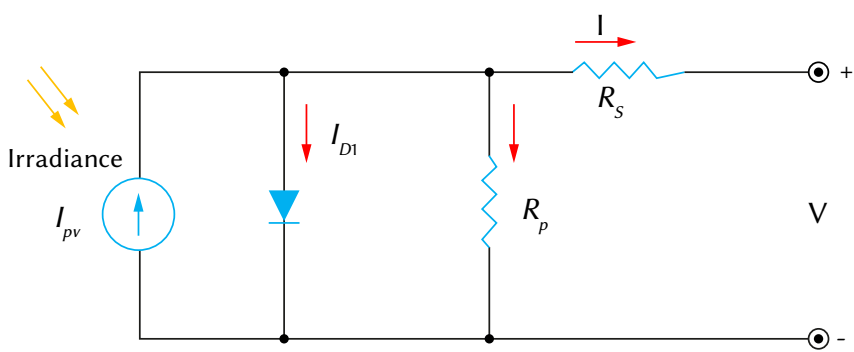

Fig. 1. Equivalent circuit of single diode model (SDM).

\section{B. Double Diode Model}

The electrical equivalent model of a double diode is similar to that of the single diode, adding the fact of having two diodes connected in parallel to the current generator. This sort of model is able to simulate the behavior of PV modules under different irradiation conditions [15]. To achieve more accuracy, DDM is highly useful even if the number of unknown parameters would be increased. Fig. 2 illustrates the equivalent circuit model of the double diode.

Similarly, the generated current is obtained by applying Kirchhoff's law, and it is described as follows:

$$
\begin{aligned}
& I=I_{p v}-I_{o 1}\left[\exp \left(\frac{q\left(V+I . R_{S}\right)}{n_{1} \cdot k \cdot T}\right)-1\right]-\ldots . \\
& I_{o 2}\left[\exp \left(\frac{q\left(V+I . R_{S}\right)}{n_{,} . k . T}\right)-1\right]-\left(\frac{V+I . R_{S}}{R_{n}}\right)
\end{aligned}
$$

Where $n_{1}$ and $n_{2}$ represent the ideality factor of diode D1 and diode D2, respectively.

The diffusion and saturation current values are indicated by $I_{\mathrm{o} 1}$ and $I_{\mathrm{o} 2}$.

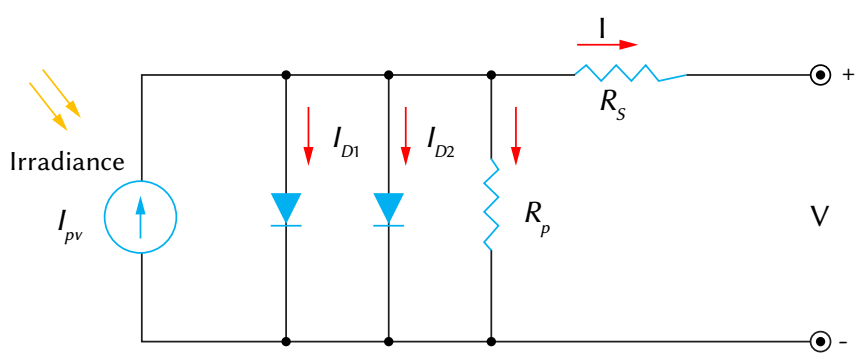

Fig. 2. Equivalent circuit of double diode model (DDM).

To ensure an efficient modeling of DDM, these parameters ( $I_{\mathrm{pv}}, I_{\mathrm{o} 1}$, $\left.I_{\mathrm{o} 2,} n_{1}, n_{2}, R_{\mathrm{s}}, R_{\mathrm{p}}\right)$ shall be determined.

\section{Problem Formulation}

To build an accurate PV mathematical model, the $(I-V)$ characteristic of PV cells is needed. The non-linear aspect of this equation conducts to a non-linear mathematical model, governed by several unknown variables. Therefore, the estimation process of these parameters $\alpha=$ $\left(I_{\mathrm{pv}}, I_{\mathrm{o} 1}, n_{1}, R_{\mathrm{s}}, R_{\mathrm{p}}\right)$ for the SDM and $\alpha=\left(I_{\mathrm{pv}}, I_{\mathrm{o} 1}, I_{\mathrm{o} 2}, n_{1,}, n_{2}, R_{\mathrm{s}}, R_{\mathrm{p}}\right)$ for the $\mathrm{DDM}$, is reformulated as a non-linear optimization problem.

To effectively resolve such a hard optimization problem, several optimization algorithms were investigated.

The performance requirements in terms of accuracy identification should be achieved through an appropriate design of an objective function that shall be minimized. The implementation cost function is described by Eq (6), which adopts the root mean square error criteria.

The difference equation between the detected current $I_{\text {det }}$ and the predicted current $I_{\text {pre }}$, which can be quantified trough several performance indexes, is defined as follows:
$J(\alpha)=I_{\text {det }}-I_{\text {pre }}\left(V_{\text {det }}, \alpha\right)$

The appropriate cost function can be provided as:

$$
R M S E=\sqrt{\frac{1}{N} \sum_{i=1}^{N}\left(J_{i}(\alpha)\right)^{2}}
$$

Where $N$ is the set of empirical detected points $\left(I_{\mathrm{i}}, V_{\mathrm{i}}\right)$.

The predicted current value is obtained by means of Eq. (1) and Eq. (4) of the SDM and DDM, as a measure of the detected voltage $\left(V_{\text {det }}\right)$ and the estimated variables, respectively.

\section{Hybrid Particle Swarm Optimization and Grey Wolf} OptIMIZER

\section{A. Standard Particle Swarm Optimization Algorithm}

Particle swarm optimization (PSO) is a metaheuristic algorithm, which is initially developed by Kennedy and Eberhart [30]. PSO was motivated by social behavior flocks' birds, which serves as a set of design variables.

The PSO technique uses $n$ particles, randomly distributed in the research space initially considered, to find an optimal solution. Each particle, representing a candidate solution, is characterized by a position and velocity.

The next position of the particle $x_{i}^{t+1}$ is obtained from the current position $x_{i}^{t}$ as well as from the new calculated velocity $v_{i}^{t+1}$.

In fact, the next velocity of each agent $v_{i}^{t+1}$ is computed as a function of its current velocity $v_{i}^{t}$, the current position $x_{i}^{t}$, the distance to the best personal particle's performance at iteration $\mathrm{t}$, pbest $_{i}$ and the distance to the best particle in the particle's neighborhood at iteration t, gbest.

$$
\begin{aligned}
& v_{i}^{t+1}=\overbrace{\begin{array}{c}
\text { w. } v_{i}^{t} \\
\text { third_part }
\end{array}}^{\text {first_part }}+\overbrace{C_{1} \cdot \text { rand }_{1} \cdot\left(\mathrm{pbest} t_{i}-x_{i}^{t}\right)}^{\text {second_part }}+\ldots . . \\
& \overbrace{C_{2} \cdot \text { rand }_{2} \cdot\left(\text { gbest }-x_{i}^{t}\right)} \\
& x_{i}^{t+1}=x_{i}^{t}+v_{i}^{t+1}
\end{aligned}
$$

Where $W$ is the inertia factor used to control the influence of particle's velocity on its next move, in order to maintain a balance between the exploration and exploitation of the search space.

$C_{1}$ and $C_{2}$ are the cognitive and the social coefficient respectively.

rand $_{1}$ and rand $_{2}$ are two random variables distributed according to a uniform distribution law in the interval [0 1 $]$.

The first part of Eq (7) provides the exploration capability of the PSO algorithm.

The second part of Eq (7) moves the particle towards the best position ever achieved by himself, and the third part of Eq (7) moves the particle according to the best position achieved by all the particles in the population.

Further, the PSO method is initialized by an initializing population of particles whose velocities are computed using Eq (7). The process update of particles' positions is defined as Eq (8). Finally, PSO will be stopped by achieving an end criterion.

\section{B. Grey Wolf Optimizer}

Motivated by grey wolves, the metaheuristic GWO imitates the hunting process and the leadership hierarchy of grey wolves [31]. Grey wolves exist at the highest level of the food chain and regarded as predators. To make sure that the hunting mechanism performs, greys wolves opt to live within the pack. 
The mathematical model of the hunting mechanism of GWO consists of a leader wolf ( $\alpha$ group), which represents the best fittest solution and a group of followers ( $\beta, \delta$ and $\gamma$ groups) that are trying to offer the best location of prey via hunting procedure.

In fact, each hunting mechanism consists of two main components parts: tracking and catching the prey, then encircling and attacking the prey until the stop of its moving act.

Over the hunting process, preys have been encircled by the grey wolves. The following equations developed in [31] simulate the encircling's behavior:

$$
\begin{aligned}
& D=\left|C * X_{p}(t)-X(t)\right| \\
& X(t+1)=X_{p}(t)-A * D
\end{aligned}
$$

Where $t$ presents the current iteration, $X_{\mathrm{p}}$ and $X$ indicate the position of prey and the location of grey wolves, respectively.

$A$ and $C$ indicate the coefficients vectors, which are computed as follows:

$$
\begin{aligned}
& A=a *\left(2 * r_{1}-1\right) \\
& C=2 * r_{2}
\end{aligned}
$$

$r_{1}$ and $r_{2}$ are random numbers, selected within the interval [0 1 ].

The component "a" shall be decreased in a linear manner starting from 2 to 0 , over the different iterations.

To discover the prey's location, alpha wolves seek to lead the grey wolves, the other wolves' groups are needed to ensure that this procedure runs perfectly.

By using this GWO metaheuristic, the best solution is guaranteed by the alpha wolves, beta and delta wolves reported the second and third-best solutions.

The process update of grey wolves' position reported in [35] is presented as:

$$
\begin{gathered}
D_{\alpha}=\left|C_{1} * X_{\alpha}-X(t)\right| \\
D_{\beta}=\left|C_{2} * X_{\beta}-X(t)\right| \\
D_{\delta}=\left|C_{3} * X_{\delta}-X(t)\right|
\end{gathered}
$$

For each iteration, the best three wolves are represented by $X_{\alpha}, X_{\beta}$, and $X_{\delta}$ :

$$
\begin{aligned}
& X_{1}=\left|X_{\alpha}-a_{1} * D_{\alpha}\right| \\
& X_{2}=\left|X_{\beta}-a_{2} * D_{\beta}\right| \\
& X_{3}=\left|X_{\delta}-a_{3} * D_{\delta}\right|
\end{aligned}
$$

In fact, the updated position of the prey is provided by the mean of three values of positions assessed as the best solutions, which is defined as follows:

$$
X_{p}(t+1)=\frac{X_{1}+X_{2}+X_{3}}{3}
$$

Attacking prey is considered as the last stage of the GWO method. The condition that guarantees this process is formulated as follows: enough closing to the prey, when the prey achieves an adequate close for values less than 1, grey wolves found themselves in an attack position of preys. This algorithm has the advantage to avoid the wolves getting catch the local minimum when the GWO approach stopped by achieving an end criterion.

\section{The Hybrid PSOGWO Algorithm}

The significantly referred variant of PSO is denoted PSOGWO. The fundamental principle of this hybridization method is to integrate the capability of social thinking $\left(g_{\text {best }}\right)$ for PSO with the local search ability of GWO.
The hybrid PSOGWO method has been examined without making changes in the basics operations of the Standard PSO and GWO techniques. In this context, the PSO algorithm is considered as the most used MH technique due to its simplicity and ease of implementation. However, when the PSO algorithm is subjected to some constraints, this technique suffers from shortcomings such as catching the local minimum. In this regard, to avoid this drawback, GWO is proposed to reduce the chance of trapping on the local minimum. In addition, this technique has the advantage of preserving a balance between the exploitation and exploration mechanisms over the optimizing process. The different steps of the hybrid PSOGWO method are illustrated in Fig. 3. PSO algorithm ensures that particles are directed to random positions with a small chance to prevent the local minimum. These directions may have present risks lead to move closer to the local minimum instead of the global minimum. Due to its exploration ability, the GWO algorithm is considered to avoid these risks by replacing these particles by the other ones having improved positions by the run of the GWO algorithm. Since the GWO technique is still used as a complement to the PSO technique, the time execution is extended. However, the successful results and the additional time required are taken into account, and the extended execution time can be considered as acceptable depending on the nature of the optimization problem that shall be resolved.

\section{Results ANd Discussion}

To prove the validity of the proposed PSOGWO approach, it is applied to determine the parameters of different solar PV equivalent circuit models, including the SDM and DDM. Three different experimental datasets are adopted. For the first case, an experimental standard dataset of a Photowatt-PWP 201. It contains 36 polycrystalline silicon cells and operated at $45^{\circ} \mathrm{C}$ and $1000 \mathrm{~W} / \mathrm{m}^{2}$ [32]. A four solar cell of STE4/100 is used for the second case study. These data are taken from [33]. The test has been performed at 22 ${ }^{\circ} \mathrm{C}$ under irradiance of $900 \mathrm{~W} / \mathrm{m}^{2}$. For the third experimental dataset, these data are extracted using FSM solar PV module at a temperature of $30{ }^{\circ} \mathrm{C}$. The number of measured voltage and current points is 21 . The experimental test rig is shown in Fig. 4. More details about the monitoring system used for recording the experimental dataset can be found [34]. Table I highlights the different specifications of PV panels that are considered in this research.

\section{A. Results of $1^{\text {st }}$ Dataset}

Based on the experimental dataset on Photowatt-PWP 201 PV module, the proposed strategy of PSOGWO is used to determine the optimal parameters of the cell for both SDM and DDM. Table II shows the maximum and minimum boundaries of each unknown parameter and optimal values of SDM and DDM parameters of Photowatt-PWP 201 PV module using PSOGWO, ALO-LW [32], PS [35] and GA [36].

For SDM, the minimum value of RMSE is achieved by PSOGWO strategy. The values of RMSE are 3.06E-03, 1.43E-02, 1.18E-02, and 6.84E03 respectively for PSOGWO, ALO-LW, PS, and GA. The coefficient of determination is 0.999952 using PSOGWO. This confirms that there is an almost perfect agreement between the estimated datasets and the experimental data. Fig. 5(a) and (b) show the experimental dataset versus the estimated respectively for both SDM and DDM. For the DDM, the RMSE and MAE are 2.87E-03 and 2.33E-03, respectively.

The absolute error against measured PV module voltage for both SDM and DDM using different strategies is shown in Fig. 6. For SDM, the maximum values for the absolute error are $0.0125,0.0066$, and 0.006 respectively for GA, PS, and PSOGWO. Whereas the maximum absolute error for DDM is 0.0056 using the proposed strategy. This also confirms the superiority of PSOGWO compared with other methods. 


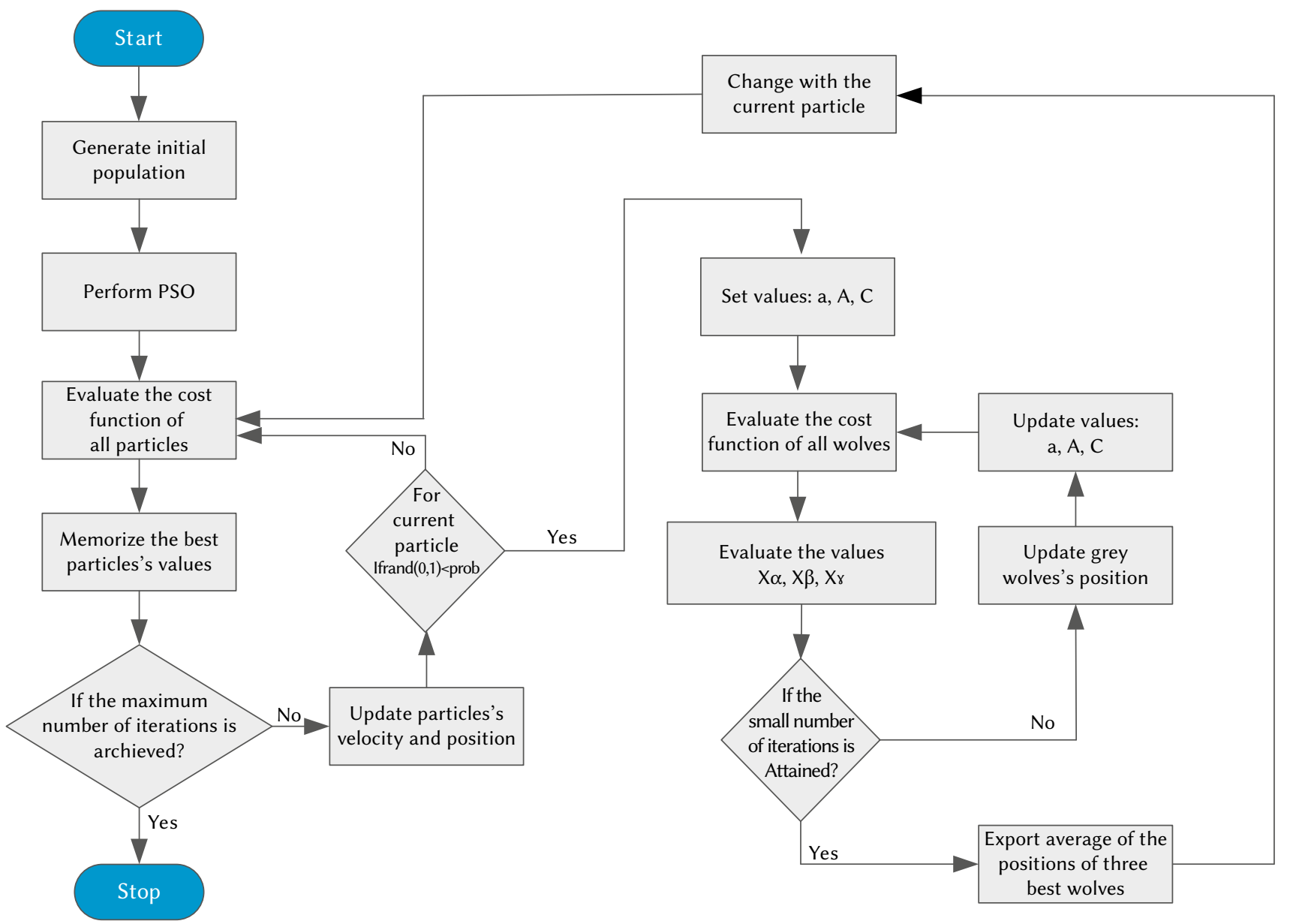

Fig. 3. The steps of PSOGWO.

Roof-monted solar photovoltaic module

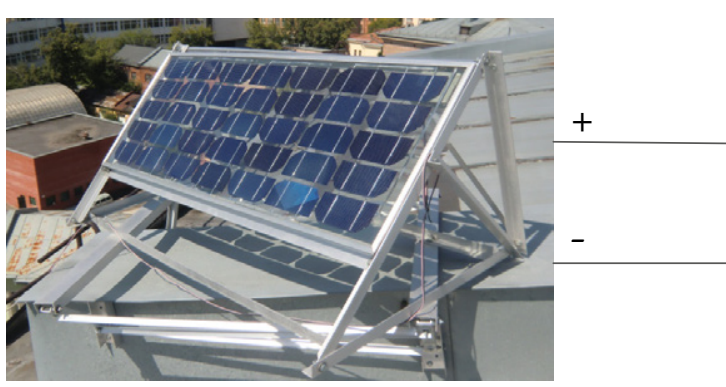

NI USB $6009-8$ inputs, 14 bit multisystem I/O data-acquisition card and electronic circuit

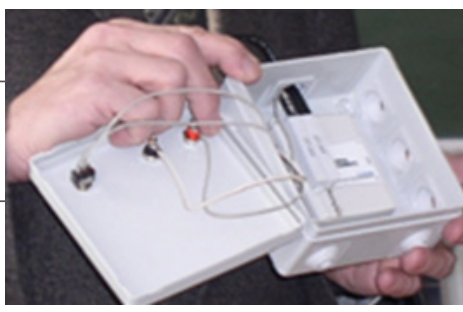

Monitoring PV system parameters using Lab-VIEW program

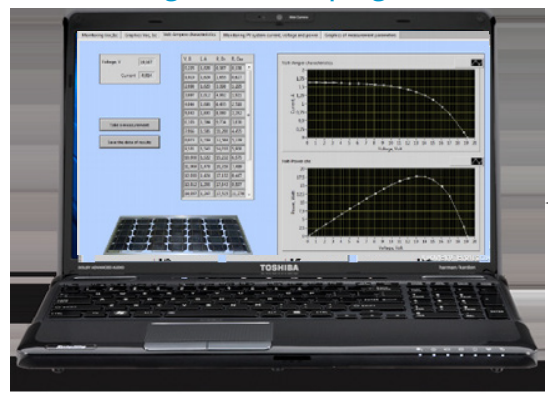

Fig. 4. The experimental test rig. 


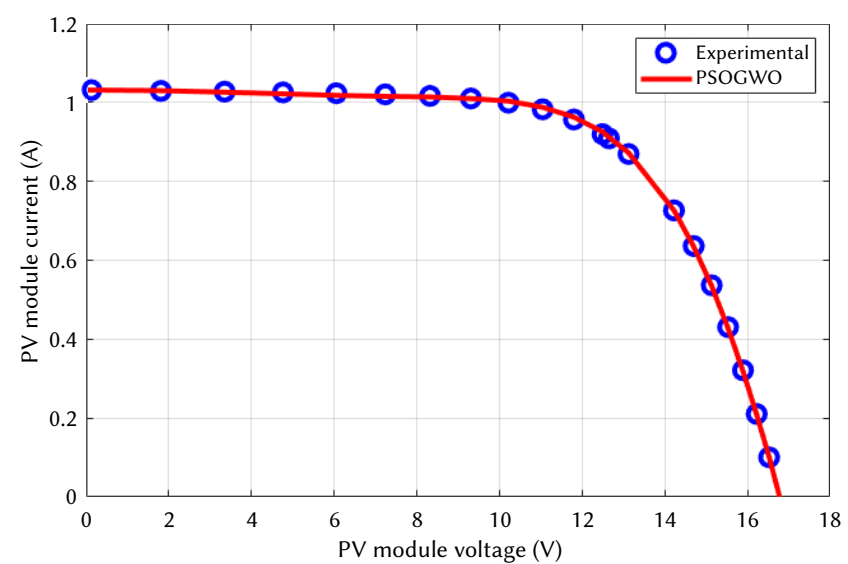

a) $\mathrm{SDM}$

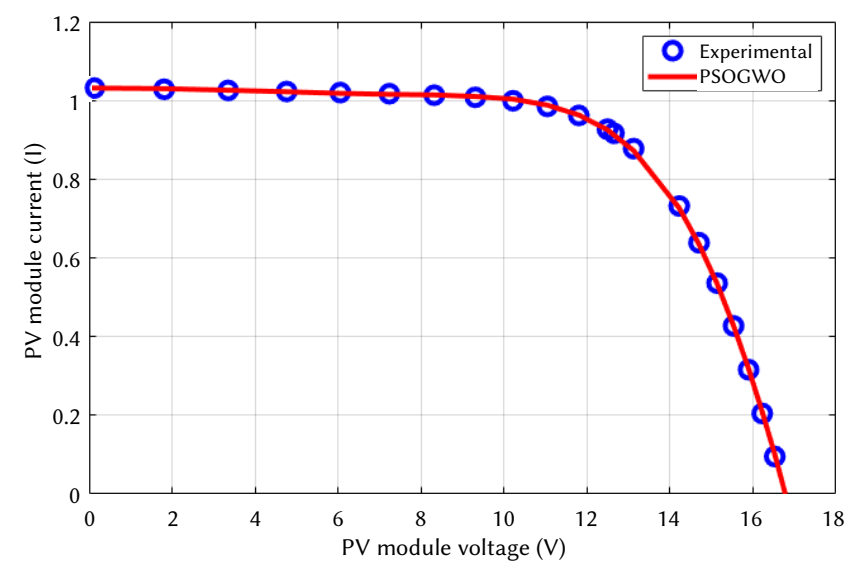

b) DDM

Fig. 5. The experimental dataset versus the estimated for Photowatt-PWP 201 PV module.

TABLE I. Specifications of Photowatt-PWP 201, STE4/100 AND FSM

\begin{tabular}{cccc}
\hline \multirow{2}{*}{ Parameter } & \multicolumn{3}{c}{ Model of solar PV panel } \\
\cline { 2 - 4 } & Photowatt PWP 201 & STE4/100 & FSM \\
\hline Number of samples & 26 & 18 & 21 \\
Test Temperature, C & 45 & 22 & 30 \\
Test radiation, W/m2 & 1000 & 900 & na \\
Short circuit current, A & 1.0315 & $26.4 \mathrm{E}-3$ & 1.105 \\
Open circuit voltage, V & 16.79 & 2.0 & 19.02 \\
Current @ MPP, A & 12.4929 & $27.7 \mathrm{E}-3$ & 0.917 \\
voltage @ MPP, V & 0.9255 & 1.6 & 14.00 \\
Number of cells & 36 & 4 & 35 \\
\hline
\end{tabular}

Fig. 7 shows the variation cost function during parameter estimation of Photowatt PWP 201 PV panel using PSOGWO strategy for both SDM and DDM. For both models, approximately 1000 iterations are required to catch the best solution. The best solution values are $3.06 \mathrm{E}-$ 03 and 2.87E-03 for SDM and DDM, respectively.

The results of the whiteness test for Photowatt PWP 201 PV panel using PSOGWO strategy are shown in Fig. 8. The main target of this test is to ensure that the selected model parameters describe the experimental dataset. It is calculated using the residual autocorrelation function (RACF) at different time lags. Considering Fig. 8, the RCAF values range from -1 to +1 .

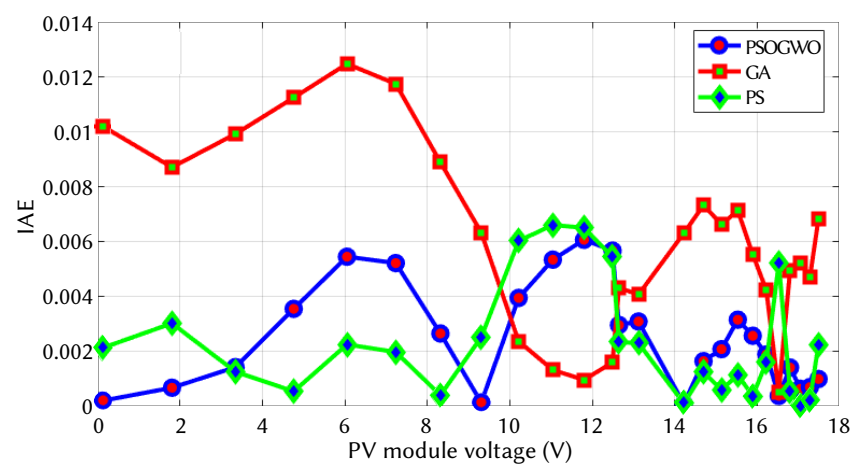

a) SDM

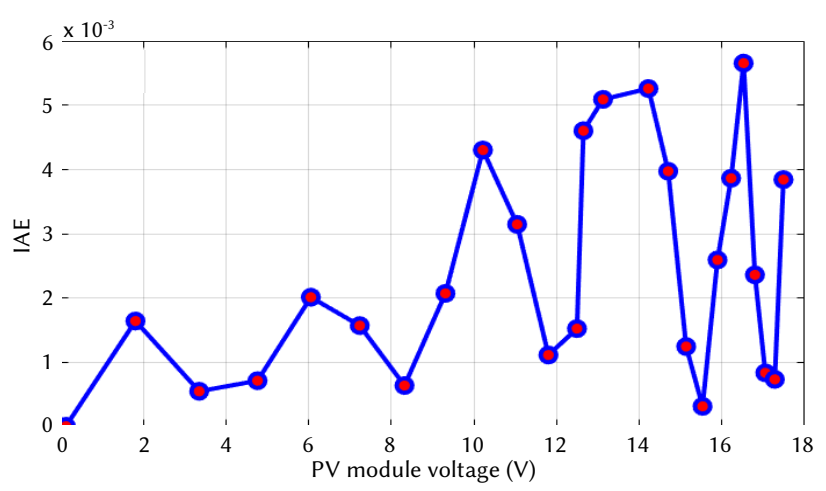

b) DDM

Fig. 6. Absolute error against measured PV module voltage for both SDM and DDM Photowatt-PWP 201 PV module using different strategies.

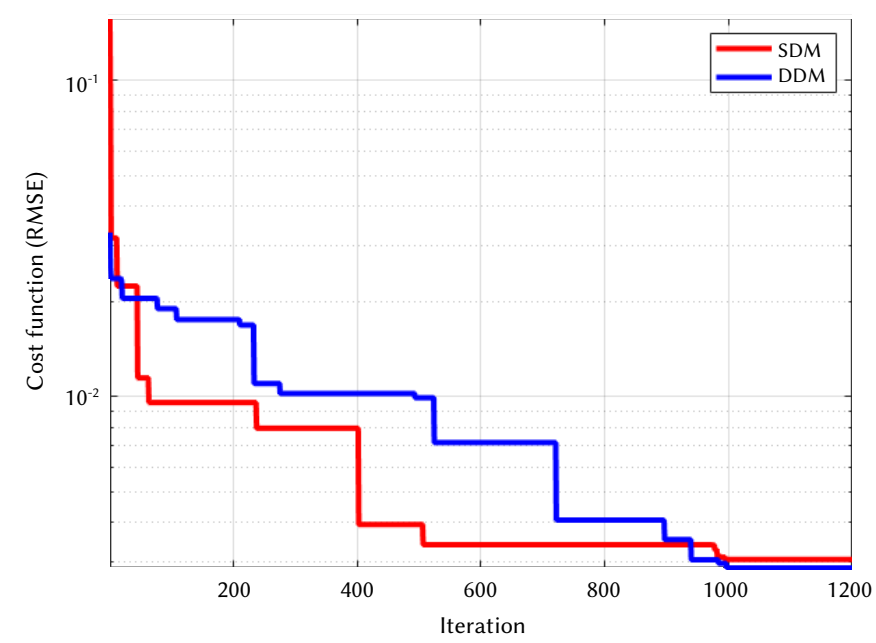

Fig. 7. The variation of cost function during parameter estimation of Photowatt PWP 201 PV panel using PSOGWO strategy.

\section{B. Results of $2^{\text {nd }}$ Dataset}

Based on the experimental dataset on STE4/100 PV solar module PV module, the proposed strategy of PSOGWO is used to determine the optimal parameters of the cell for both SDM and DDM. The number of I-V points is 22. Table III shows the maximum and minimum boundaries of each unknown parameter and optimal values of SDM parameters of STE4/100 PV solar module using PSOGWO, GWO, and ACT [33].

The minimum value of RMSE is achieved by PSOGWO strategy. The values of RMSE are 3.0574E-4, 6.0221E-4, and 3.33925E-4, respectively, for PSOGWO, GWO, and ACT method. The best coefficient of 


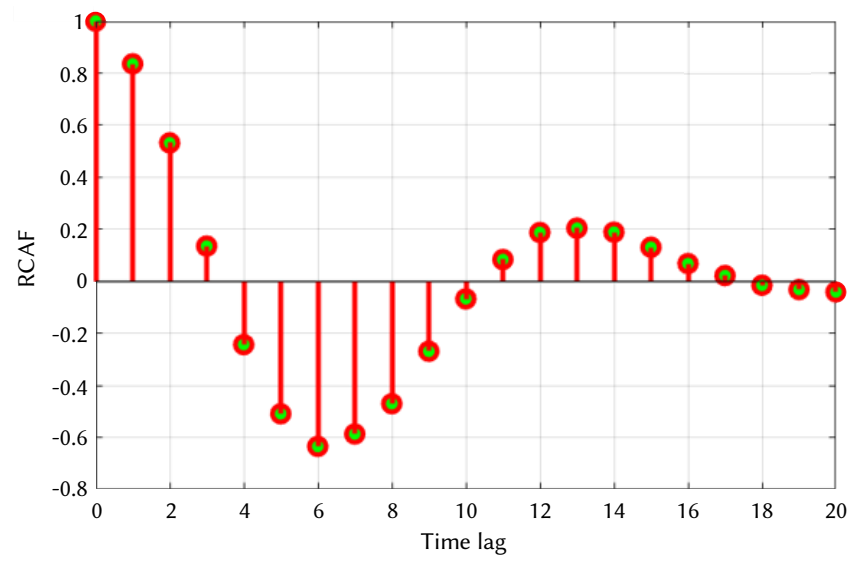

a) SDM

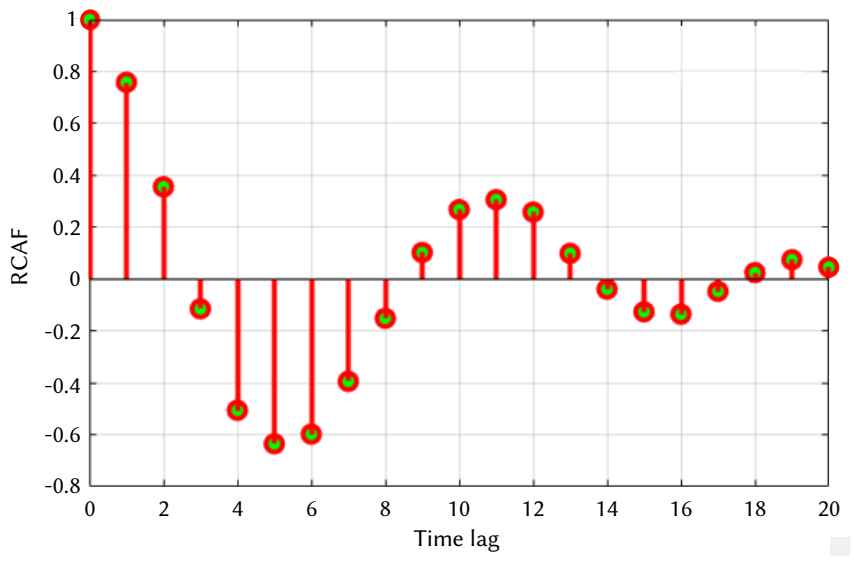

b) DDM

Fig. 8. RCAF results of SDM and DDM for Photowatt-PWP 201 PV module using SFS strategy.

TABLE II. Boundaries and Optimal Values of SDM and DDM Parameters of Photowatt-PWP 201 PV Module

\begin{tabular}{|c|c|c|c|c|c|c|c|}
\hline \multirow{2}{*}{ Parameter } & \multicolumn{2}{|c|}{ Boundary } & \multicolumn{3}{|c|}{ Optimal parameters (SDM) } & \multicolumn{2}{|c|}{ DDM } \\
\hline & Min. & Max. & PSOGWO & ALO-LW [32] & PS [35] & GA[36] & PSOGWO \\
\hline$I_{\mathrm{sc}}(\mathrm{A})$ & 0.0 & 1.5 & 1.0328 & 1.03354 & 1.0313 & 1.0441 & 1.0343 \\
\hline$I \mathrm{o}_{1}(\mathrm{~A})$ & $1.0 \mathrm{e}-9$ & $1.0 \mathrm{e}-3$ & $5.736 \mathrm{e}-06$ & 4.53123E-6 & $3.1756 \mathrm{E}-6$ & $3.4360 \mathrm{E}-6$ & $9.2835 \mathrm{e}-07$ \\
\hline$I_{2}(A)$ & $1.0 \mathrm{e}-9$ & $1.0 \mathrm{e}-3$ & $\mathrm{Na}$ & na & na & na & $3.4626 \mathrm{e}-07$ \\
\hline$a_{1}$ & 0.0 & 3.0 & 1.4074 & 49.8068 & 48.2889 & 48.5862 & 1.2237 \\
\hline$a_{2}$ & 0.0 & 3.0 & $\mathrm{Na}$ & na & na & na & 1.7401 \\
\hline$R_{\mathrm{s}}(\Omega)$ & 0.0 & 5.0 & 1.1257 & 1.1246 & 1.2053 & 1.1968 & 1.3398 \\
\hline$R_{\mathrm{sh}}(\Omega)$ & 0.0 & 2000 & 868.165 & 415.529 & 714.286 & 55.55 & 535.667 \\
\hline RMSE & & & $3.06 \mathrm{E}-03$ & $1.43 \mathrm{E}-02$ & $1.18 \mathrm{E}-02$ & $6.84 \mathrm{E}-03$ & $2.87 \mathrm{E}-03$ \\
\hline MAE & & & $2.42 \mathrm{E}-03$ & $1.69 \mathrm{E}-01$ & $2.27 \mathrm{E}-03$ & $6.14 \mathrm{E}-03$ & $2.33 \mathrm{E}-03$ \\
\hline$R^{2}$ & & & 0.999952 & na & na & na & 0.999957 \\
\hline
\end{tabular}

TABLE III. Boundaries and Optimal Values of SDM Parameters of STE4/100 PV Solar Module

\begin{tabular}{cccccc}
\hline \multicolumn{4}{c}{ Boundary } & \multicolumn{2}{c}{ Optimal parameters } \\
\hline parameter & Min. & Max. & PSOGWO & GWO & ACT [33] \\
\hline$I_{\mathrm{sc}}(\mathrm{A})$ & 0.0 & 1.0 & $26.419 \mathrm{E}-3$ & $26.1449 \mathrm{E}-3$ & $0.024 .64 \mathrm{E}-3$ \\
$I_{1}(\mathrm{~A})$ & $1.0 \mathrm{E}-10$ & $1.0 \mathrm{E}-5$ & $9.4392 \mathrm{E}-09$ & $1.00 \mathrm{e}-08$ & $1.29814 \mathrm{E}-8$ \\
$a_{1}$ & 0.0 & 2.0 & 1.3369 & 1.58663 & 1.0304 \\
$R_{\mathrm{s}}(\Omega)$ & 0.0 & 5.0 & 0.7322 & 0.001 & 2.5568 \\
$R_{\mathrm{sh}}(\Omega)$ & 0.0 & 5000 & 2488.087 & 4900 & 2184.82 \\
$\mathrm{RMSE}$ & & & $3.0574 \mathrm{E}-4$ & $6.0221 \mathrm{E}-4$ & $3.33925 \mathrm{E}-4$ \\
$\mathrm{MAE}$ & & & $2.13123 \mathrm{E}-04$ & $3.9455 \mathrm{E}-4$ & $1.98027 \mathrm{E}-4$ \\
$R^{2}$ & & & 0.99828 & 0.993328 & 0.99800 \\
\hline
\end{tabular}

determination is 0.99828. It is achieved by using PSOGWO. This confirms that there is an almost perfect agreement between the estimated datasets and the experimental data. Fig. 9 shows the experimental dataset versus the estimated respectively for SDM.

The absolute error against measured PV module voltage for SDM using different strategies is shown in Fig. 9. As shown in Fig. 10, the maximum values for the absolute error are 7.15E-04, 1.50E-03, and $1.00 \mathrm{E}-03$, respectively for PSOGWO, GWO, and ACT method. This confirms the superiority of PSOGWO compared with GWO and ACT method. The variation cost function during parameter estimation of STE4/100 PV panel using PSOGWO and GWO strategies for SDM is illustrated in Fig. 11. The best solution values are 3.0574E-4 and 6.0221E-4, respectively, for PSOGWO and GWO strategies. 


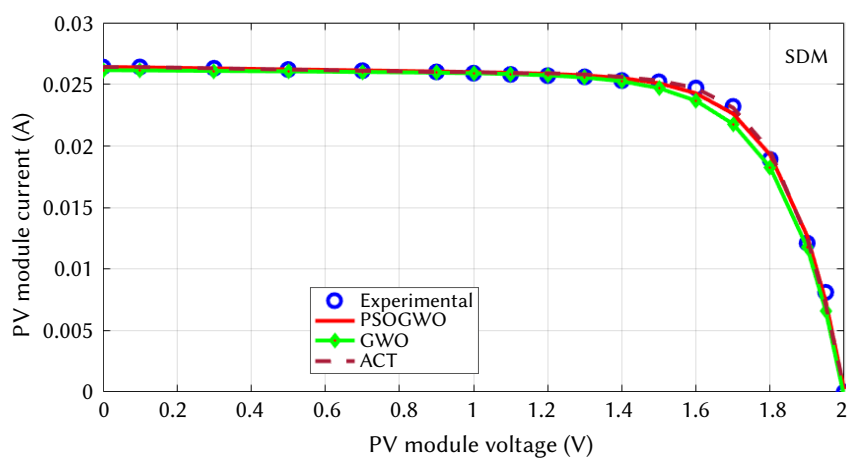

Fig. 9. The experimental dataset versus the estimated for STE4/100 PV panel.

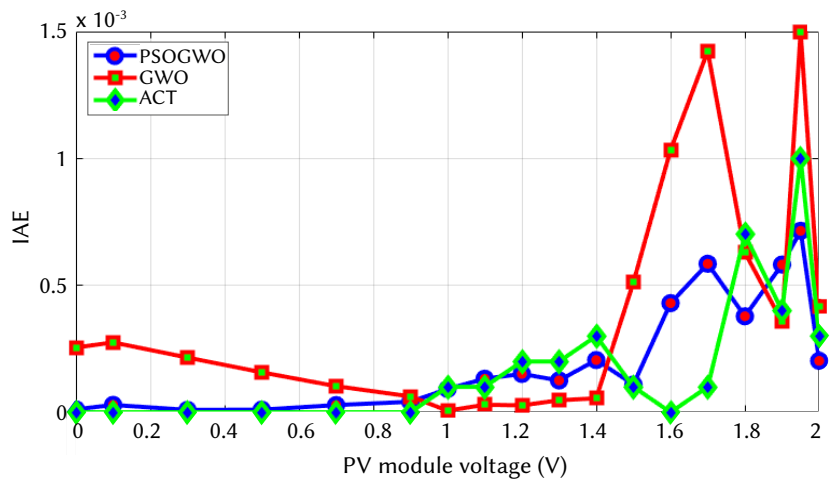

Fig. 10. Absolute error against measured PV module voltage of SDM for STP4/100 PV panel using different strategies.

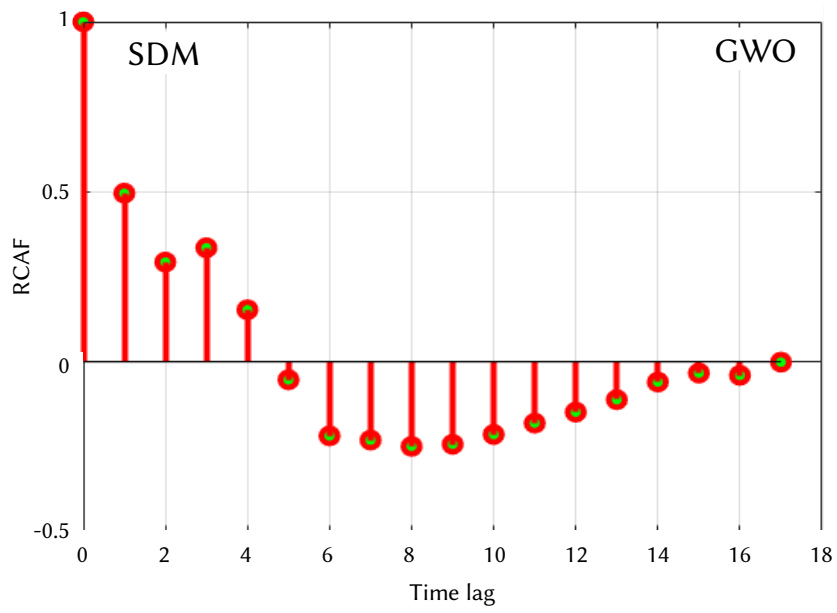

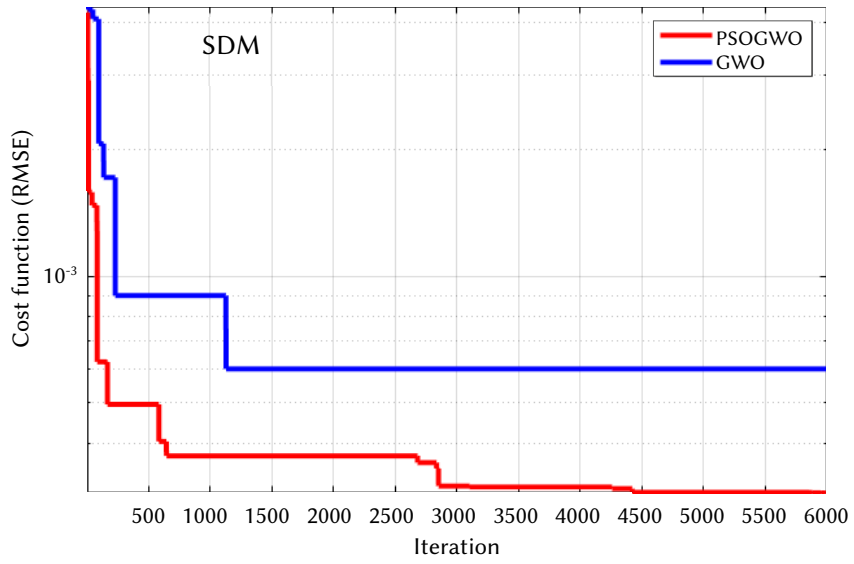

Fig. 11. The variation cost function during parameter estimation of STP4/100 PV panel using PSOGWO and GWO strategies.

The results of the whiteness test for STE4/100 PV panel using both PSOGWO and GWO strategies are shown in Fig. 12. It is very clear that the RCAF values range from -1 to +1 for both strategies.

\section{Results of $3^{\text {rd }}$ Dataset}

Based on the experimental dataset on FSM solar module, the proposed strategy of PSOGWO is used to determine the optimal parameters of the cell for both SDM and DDM. Table IV shows the maximum and minimum boundaries of each unknown parameter and optimal values of SDM and DDM parameters of FSM PV solar module using PSOGWO and GWO strategies.

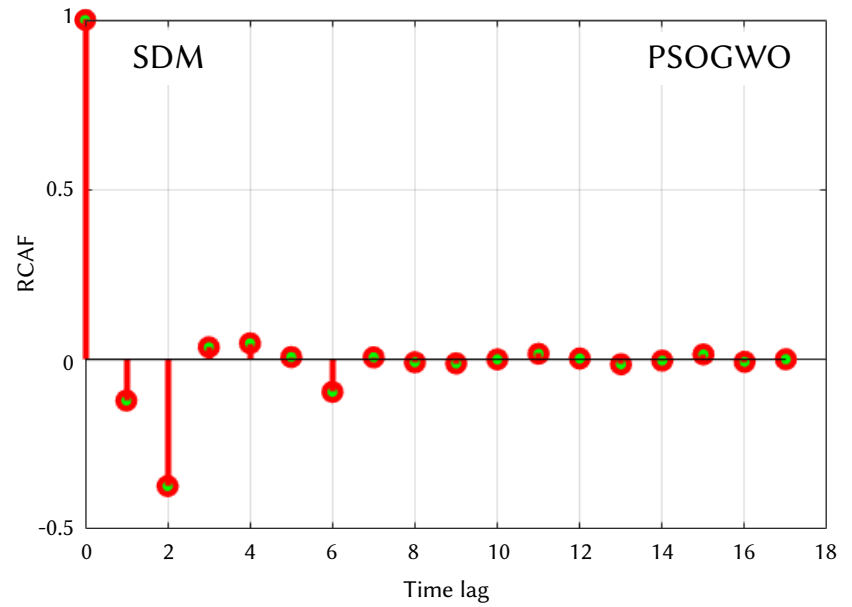

Fig. 12. RCAF results for STE4/100 PV panel using PSOGWO and GWO strategies.

TABLE IV. Boundaries and Optimal Values of SDM and DDM Parameters of FSM PV Module Using PSOGWO and GWO Strategies

\begin{tabular}{|c|c|c|c|c|c|c|}
\hline \multirow{3}{*}{ Parameter } & \multicolumn{2}{|c|}{ Boundary } & \multicolumn{4}{|c|}{ Optimal parameters } \\
\hline & \multirow[t]{2}{*}{ Min. } & \multirow[t]{2}{*}{ Max. } & \multicolumn{2}{|c|}{ SDM } & \multicolumn{2}{|c|}{ DDM } \\
\hline & & & PSOGWO & GWO & PSOGWO & GWO \\
\hline$I_{\mathrm{sc}}(\mathrm{A})$ & 0 & 2 & 1.1132 & 1.1315 & 1.11027 & 1.12253 \\
\hline $\mathrm{Io}_{1}(\mathrm{~A})$ & $1.0 \mathrm{E}-8$ & $1.0 \mathrm{E}-3$ & $1.012 \mathrm{E}-04$ & $1.819 \mathrm{E}-04$ & $5.40 \mathrm{E}-09$ & $1.07 \mathrm{E}-06$ \\
\hline $\mathrm{Io}_{2}(\mathrm{~A})$ & $1.0 \mathrm{E}-8$ & $1.0 \mathrm{E}-3$ & na & na & $1.02 \mathrm{E}-04$ & $1.081 \mathrm{E}-03$ \\
\hline$a_{1}$ & 0.0 & 3.0 & 2.232 & 2.275 & 1.8583 & 2.9803 \\
\hline$a_{2}$ & 0.0 & 3.0 & na & na & 2.23125 & 2.9917 \\
\hline$R_{\mathrm{s}}(\Omega)$ & 0.0 & 5.0 & 1.3357 & 2.211 & 1.36741 & 0.9787 \\
\hline$R_{\mathrm{sh}}(\Omega)$ & 0.0 & 5000 & 1430.439 & 4980.36 & 3918.684 & 4907.89 \\
\hline RMSE & & & $9.14 \mathrm{E}-03$ & $2.99 \mathrm{E}-02$ & 8.97E-03 & $2.52 \mathrm{E}-02$ \\
\hline MAE & & & 7.63E-03 & $2.12 \mathrm{E}-02$ & 7.38E-03 & $1.95 \mathrm{E}-02$ \\
\hline$R^{2}$ & & & 0.9991 & 0.9901 & 0.9991 & 0.9929 \\
\hline
\end{tabular}



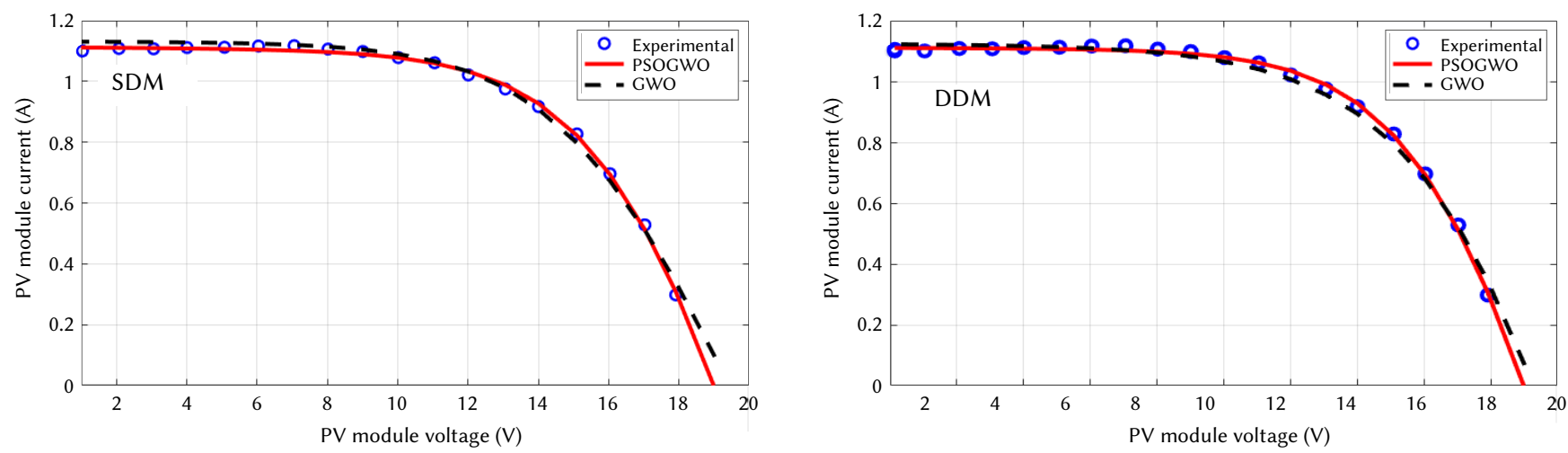

Fig. 13. The experimental dataset versus the estimated for FSM PV module for both SDM and DDM using PSOGWO and GWO strategies.
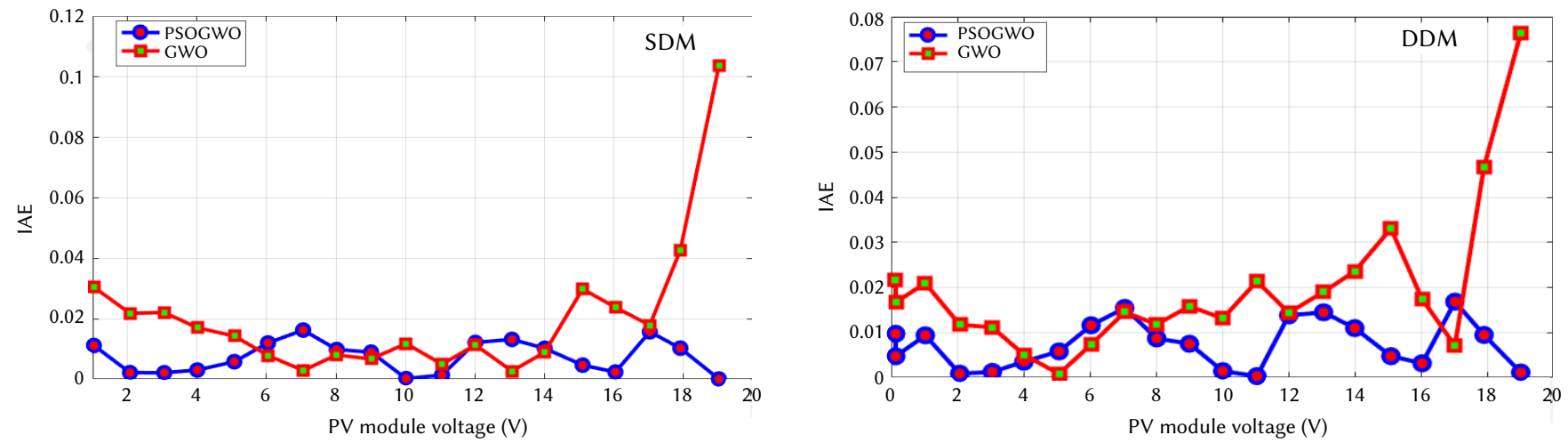

Fig. 14. Absolute error against measured PV module voltage for both SDM and DDM for FSM PV module using PSOGWO and GWO strategies.
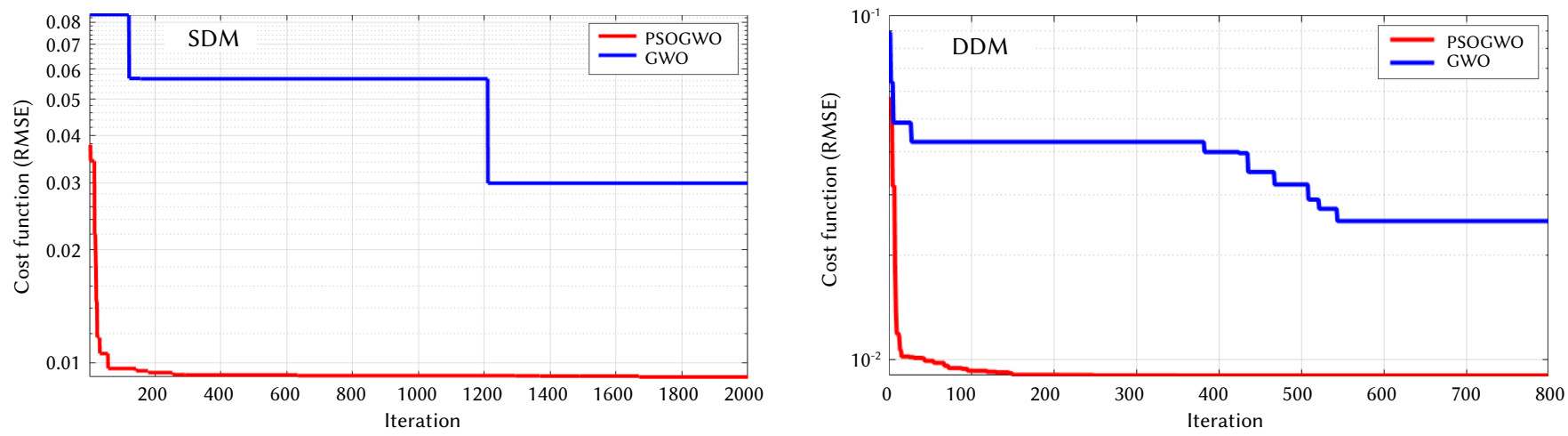

Fig. 15. The variation cost function during parameter estimation of FSM PV module using SFS strategy.

The minimum value of RMSE is achieved by PSOGWO strategy. For SDM, the values of RMSE are 7.63E-03 and 2.12E-02, respectively, for PSOGWO and GWO. Whereas, for DDM, the values of RMSE are 7.38E-03 and 1.95E-02 respectively for PSOGWO and GWO. The best coefficient of determination is 0.9991 . It is achieved by using PSOGWO for both SDM and DDM. This confirms that there is an almost perfect agreement between the estimated datasets and the experimental data. Fig. 13 shows the experimental dataset versus the estimated, respectively, for both SDM and DDM.

The absolute error against measured PV module voltage for both SDM and DDM using PSOGWO and GWO strategies is shown in Fig. 14. For the SDM, the maximum values for the absolute error are
0.0162 and 0.1035 , respectively, for PSOGWO and GWO. Whereas for the DDM, the maximum values for the absolute error are 0.0168 and 0.0764 , respectively, for PSOGWO and GWO. This confirms the superiority of PSOGWO compared with GWO.

The variation of cost function during parameter estimation of FSM PV panel using PSOGWO and GWO strategies for both SDM and DDM is illustrated in Fig. 15. For the SDM, the best solution values are 9.14E-03 and 2.99E-02 respectively for PSOGWO and GWO strategies. Whereas for DDM as shown in Fig. 15(b), the best solution values are 8.97E-03 and 2.52E-02, respectively, for PSOGWO and GWO strategies. This confirms the superiority of PSOGWO compared with GWO for both SDM and DDM. 

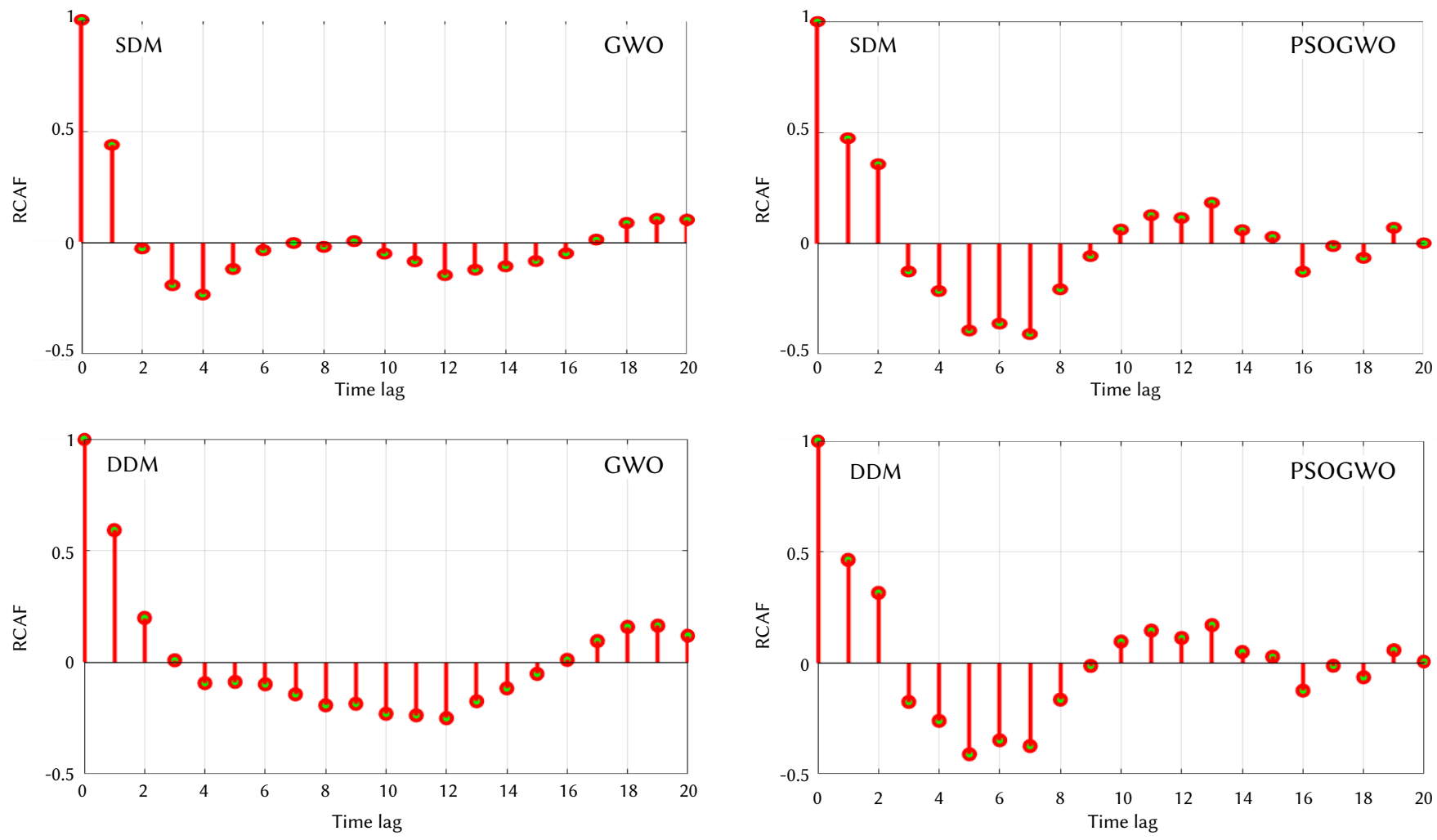

Fig. 16. RCAF results for FSM PV module using PSOGWO and GWO strategies.

The results of the whiteness test for STE4/100 PV panel using both PSOGWO and GWO strategies are shown in Fig. 16. It is very clear that the RCAF values range from -1 to +1 for both strategies.

\section{CONCLUSION}

Application of a hybrid particle swarm optimization (PSO) and grey wolf optimizer (WGO) in determining the optimal internal parameters of single-diode and double-diode models of a solar photovoltaic panel is presented for the first time in this paper, as far as the author know. Based on the experimental datasets of voltage-current curves, these internal parameters are determined. Three different PV panels are used to validate the propped strategy. The root mean square error, mean absolute error, and coefficient of determination are used as benchmark criteria for the comparison with other methods. For example, with the first dataset, in the case of SDM, the minimum value of RMSE is achieved by PSOGWO strategy. The values of RMSE are 3.06E-03, 1.43E-02, 1.18E-02, and 6.84E-03 respectively for PSOGWO, ALO-LW, PS, and GA. The coefficient of determination is 0.999952 using PSOGWO. This confirms that there is an almost perfect agreement between the estimated datasets and the experimental data. For all considered cases, the obtained results confirmed the superiority of PSOGWO compared with other methods.

\section{ACKNOWLEDGMENT}

This project was supported by the Deanship of Scientific Research at Prince Sattam Bin Abdulaziz University under the research project No $2020 / 01 / 11742$.

\section{REFERENCES}

[1] K. Ishaque, Z. Salam, H.Taheri. "Simple, fast and accurate two-diode model for photovoltaic modules," Solar Energy Materials Solar Cells, vol.
95, pp. 586-594, 2011.

[2] HGG. Nunes, JAN. Pombo, SJPS. Mariano, MRA. Calado and JAM. Felippe de Souza. "A new high performance method for determining the parameters of PV cells and modules based on guaranteed convergence particle swarm optimization," Applied Energy, vol. 211, pp. 774-791, 2018.

[3] J. Ma, Z. Bi, TO. Ting, S. Hao, W. Hao. "Comparative performance on photovoltaic model parameter identification via bio-inspired algorithms," Solar Energy, vol. 13, pp. 606-616, 2016.

[4] A. Ayang, W. René, O.Mohand, D. Noël, S. Ndjakomo Essiane, P. Joseph Kessel, and E. Gabriel . "Maximum likelihood parameters estimation of single-diode model of photovoltaic generator," Renewable Energy, vol. 130, pp. 111-121, 2019.

[5] A. Chatterjee, K. Ali, and K. Dhruv. "Identification of photovoltaic source models," IEEE Transactions on Energy Conversion, vol. 26, no.3, pp. 883889, 2011.

[6] AK. Tossa, YM. Soro, Y. Azoumah, D. Yamegueu. "A new approach to estimate the performance and energy productivity of photovoltaic modules in real operating conditions,"Solar Energy, vol. 10, pp. 543-560, 2014.

[7] T. Easwarakhanthan, J. Bottin, I. Bouhouch, C. Boutrit ."Nonlinear minimization algorithm for determining the solar cell parameters with microcomputers," International fournal of Solar Energy, vol.4, no.1, pp. 1-12, 1986.

[8] M. Chegaar, Z. Ouennoughi, A. Hoffmann. "A new method for evaluating illuminated solar cell parameters, "Solid-State Electron, vol.45, pp. 293296, 2001.

[9] S.A. Blaifi, M. Samir, T. Bilal and S. Abdelhakim. "An enhanced dynamic modeling of PV module using Levenberg-Marquardt algorithm," Renewable Energy, vol. 135, pp. 745-760, 2019.

[10] S. Chen, F. Saeid Gholami and L. Sebastian. "Photovoltaic cells parameters extraction using variables reduction and improved shark optimization technique," International fournal of Hydrogen Energy, 2020.

[11] JA. Jervase, H. Bourdoucen, A. Al-Lawati. "Solar cell parameter extraction using genetic algorithms," Measurement Science and Technology, vol. 12, no.11, pp. 1922-1925, 2001.

[12] D. Oliva, A. A. Ewees, M. A. E. Aziz, A. E. Hassanien, M. Peréz-Cisneros. "A chaotic improved artificial bee colony for parameter estimation of photovoltaic cells," Energies, vol.10, pp. 865, 2017. 
[13] R. Wang, Y. Zhan, H. Zhou. "Application of artificial bee colony in model parameter identification of solar cells," Energies, vol.8, no.8, pp. 7563$7581,2015$.

[14] M. Jamadi, F. Merrikh-Bayat, M. Bigdeli. "Very accurate parameter estimation of single- and double-diode solar cell models using a modified artificial bee colony algorithm," International fournal Energy Environmental Engineering, vol. 7, no.1, pp. 13-25, 2016.

[15] V. Khanna, B. K. Das, D. Bisht, Vandana, P. K. Singh. "A three diode model for industrial solar cells and estimation of solar cell parameters using PSO algorithm," Renewable Energy, vol. 78, pp. 105-113, 2015.

[16] R. Muralidharan. "Parameter extraction of solar photovoltaic cells and modules using current-voltage characteristics," International fournal Ambient Energy, vol.38, no.5, pp. 509-513, 2017.

[17] J. Ma, K. L. Man, S-U. Guan, T. O. Ting, P. W. H. Wong. "Parameter estimation of photovoltaic model via parallel particle swarm optimization algorithm," International fournal of Energy Research, vol.40, no.3, pp. 343352, 2016.

[18] L. Guo, Z. Meng, Y. Sun, L. Wang "Parameter identification and sensitivity analysis of solar cell models with cat swarm optimization algorithm," Energy Conversion and Management, vol.108, pp. 520-528, 2016.

[19] A. Askarzadeh, A. Rezazadeh. "Parameter identification for solar cell models using harmony search-based algorithms," Solar Energy, vol. 86, no.11, pp. 3241-3249, 2012.

[20] F. Dkhichi, B. Oukarfi, A. Fakkar, N. Belbounaguia. "Parameter identification of solar cell model using Levenberg-Marquardt algorithm combined with simulated annealing," Solar Energy, vol. 110, pp. 781-788, 2014.

[21] Z. Chen, L. Wu, P. Lin, Y. Wu, S. Cheng. "Parameters identification of photovoltaic models using hybrid adaptive Nelder-Mead simplex algorithm based on eagle strategy," Applied Energy, vol.182, pp. 47-57, 2016.

[22] N. F. Abdul Hamid, N. A. Rahim, J. Selvaraj. "Solar cell parameters identification using hybrid Nelder-Mead and modified particle swarm optimization," Journal of Renewable and Sustainable Energy, vol.8, pp. $1-21,2016$.

[23] X. Chen, B. Xu, C. Mei, Y. Ding, K. Li. "Teaching-learning-based artificial bee colony for solar photovoltaic parameter estimation," Applied Energy, vol. 212, pp. 1578-1588, 2018.

[24] K. Yu, B. Qu, C. Yue, S. Ge, X. Chen, J. Liang ."A performance-guided jaya algorithm for parameters identification of photovoltaic cell and module," Applied Energy, vol. 237, pp. 241-257, 2019.

[25] D. Oliva, M. A. El Aziz, A. E. Hassanien. "Parameter estimation of photovoltaic cells using an improved chaotic whale optimization algorithm," Applied Energy, vol. 200, pp. 141-154, 2017.

[26] A. M. Beigi, A. Maroosi. "Parameter identification for solar cells and module using a Hybrid Firefly and Pattern Search Algorithms," Solar Energy, vol.171, 2018.

[27] C. Saravanan, M.A. Panneerselvam. "A comprehensive analysis for extracting single diode PV model parameters by hybrid GA-PSO algorithm," International fournal of Computer Applications, vol.78, no.8, pp. 16-19, 2013.

[28] H. Nunes, J. Pombo, S. Mariano, M. Calado, J. F. de Souza. "A new high performance method for determining the parameters of pv cells and modules based on guaranteed convergence particle swarm optimization," Applied Energy, vol. 211, pp. 774-791, 2018.

[29] D. Yousri, T. S. Babu, D. Allam, V. K. Ramachandaramurthy, M. B. Eteiba. "Fractional chaotic ensemble particle swarm optimizer for identifying the single, double, and three diode photovoltaic models' parameters," Energy, 2020.

[30] J. Kennedy and R. C. Eberhart. "Particle swarm optimization," in Proceedings of IEEE international conference on neural networks, 1995, vol.4, pp. 1942-1948.

[31] S. M. Mirjalili, A. Lewis. "Grey wolf optimizer," Advances in Engineering Software, vol. 69, pp. 46-61, 2014.

[32] G. K. Harish Kumar. "Modeling of solar cell under different conditions by ant lion optimizer with LambertW function," Applied Soft Computing, vol.71, pp. 141-151, 2018, doi : 10.1016/J.ASOC.2018.06.025.

[33] F. Fahmi, Muhammad and al. "Simple and efficient estimation of photovoltaic cells and modules parameters using approximation and correction technique," PLOS, 2019, doi: 10.1371/journal.pone.0216201.
[34] H. Rezk, I. Tyukhov, M. Al-Dhaifallah, A. Tikhonov "Performance of data acquisition system for monitoring PV system parameters," Measurement, vol. 104, pp. 204-211.

[35] M. F. AlHajri, K. M. El-Naggar, M. R. AlRashidi, A. K. Al-Othman. "Optimal extraction of solar cell parameters using pattern search," Renewable Energy, vol. 44, pp. 238-245, 2012.

[36] M. R. AlRashidi, M. F. AlHajri, K. M. El-Naggar, A. K. Al-Othman. "A new estimation approach for determining the I-V characteristics of solar cells," Solar Energy, vol. 85, pp.1543-1550, 2011.

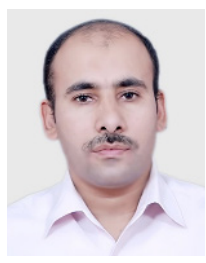

Hegazy Rezk

Hegazy Rezk received the B. Eng. and M. Eng. degrees in electrical engineering from Minia University, EGYPT in 2001 and 2006 respectively, and his $\mathrm{PhD}$ from Moscow Power Engineering Institute, Moscow. He was a postdoctoral research fellow in Moscow State University of Mechanical Engineering, Russia for 6 months. Dr. Hegazy was a visiting Researcher at Kyushu University, Japan, for one year. Currently, Hegazy Rezk is Associate Professor in Electrical Engineering Department, Collage of Engineering at Wadi Addwaser, Prince Sattam University, Saudi Arabia. He authored more than 100 technical papers. His present research interests include renewable energy, smart grid, hybrid systems, power electronics, Optimization and artificial intelligence.

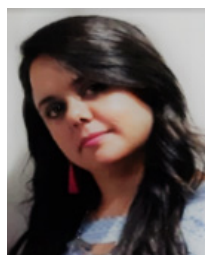

\section{Jouda Arfaoui}

Jouda Arfaoui was born in Tunisia, in 1986. She received the Master's degree in Electronics from the Faculty of Sciences of Tunis in 2012. On May 2018, she received her PhD. Her research interests include renewable energy resources, fuzzy control of several applications, power system control and optimization.

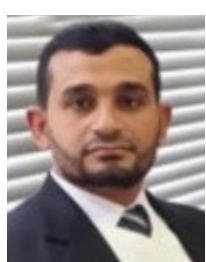

\section{Mohamed R. Gomaa}

Mohamed R. Gomaa currently employing as Assis. Prof. of Thermal and Renewable energy, Mechanical Engineering at Benha Faculty of Engineering, Benha University, Banha, Egypt. I have awarded my PhD from SEUA (Polytechnic), Yerevan, Armenia on December 2012 in the field of Renewable Energy Systems. I had completed my MSc in the field of Fluid Mechanics on March 2007 from ElMinia University, Egypt. Currently, my research interests in the field of Thermal and Renewable energy systems, absorption, desalination and air-conditioning systems. 